\title{
A PRINCIPAL COMPONENT ANALYSIS OF KNOWLEDGE MANAGEMENT SUCCESS FACTORS IN CONSTRUCTION FIRMS IN NIGERIA
}

\author{
Taiwo F. ADEGBEMBO ${ }^{1}$, Oluwaseyi AWODELE ${ }^{2}$, and Ayodeji OKE ${ }^{s}$ \\ ${ }^{1}$ Department of Quantity Surveying, \\ Federal University of Technology, Akure, Ondo State, Nigeria
}

Email: tfadegbembo@futa.edu.ng무 oaawodele@futa.edu.ng²; aeoke@futa.edu.ng³

\begin{abstract}
Construction firms are knowledge-intensive organisations as employees use knowledge in their day to day activities; however, managing this knowledge is essential for improved service delivery. Knowledge Management (KM) has been affirmed to be of great benefit and improve the performance of organisations and particularly quantity surveying firms in Nigeria so, therefore, the need to assess the factors critical to the implementation of KM. Quantitative data was collected through the use of questionnaire from eighty-six quantity surveyors from quantity surveying firms in the southwestern geopolitical zone of Nigeria which comprises of six states using census sampling. Descriptive and inferential statistics were used to analyse the data collected, and the result discussed. Mean Item Score was used to rank the factors while data reduction technique was used to ascertain the factors critical to the implementation of KM. The Kaiser-Meyer-Olkin measure of sampling adequacy and Bartlett's test of sphericity were conducted before the data were subjected to principal component analysis and the results indicated that the data set is suitable for factor analysis. Five constructs of CSF, namely; Organisation and Leadership, Resources, Management involvement, Information technology and culture were developed from the Principal Component Analysis (PCA) with a significant value ranging from $0.524-0.776$. The reliability of each construct was tested using Cronbach Alpha coefficient, and the values arrived at are; 0.87, 0.885, 0.882, 0.903 and 0.749 respectively. The study revealed that the significance of $\mathrm{KM}$ critical success factors is well acknowledged by quantity surveyors in quantity surveying firms and the findings contributed to knowledge by introducing five factors critical to the success of KM. The study recommends that these factors should be given adequate attention for successful KM implementation in quantity surveying firms in Nigeria.
\end{abstract}

Keywords: Critical success factors, Knowledge management, Principal component analysis, Nigeria

\section{INTRODUCTION}

The construction industry, according to Hsu (2008), is a knowledge-intensive industry, because the industry uses the skills, knowledge and experience of individuals in its day to day activities. The construction industry has become more and more complex with challenges as a result of globalisation, internalisation of markets, liberalisation of trades, deregulation and knowledge economy (Hari, Egbu \& Kumar, 2005). This knowledge-based economy requires that good practices are available in organisations to improve the effectiveness of the organisation (Omotayo, 2015). In facing these challenges, construction companies need to have appropriate strategies to stay relevant in the industry, and KM has been identified as one of such strategies. Organisations are, therefore, dependent on applying 
KM along with natural resources and tangible assets to achieve high performance (Lee \& Sukoco, 2007).

According to Omotayo (2015), organisations have stopped to compete entirely on capital and financial strength but now compete based on the knowledge possessed by the organisation as knowledge has become the new competitive advantage in business (Okunoye, 2003). As such, knowledge ought to be protected, nurtured and shared among the people who work together within the organisation. Knowledge is considered the most valuable and precious asset of organisations (Sharif, Yaqub, Khan \& Javed, 2014; Idris \& Kolawole, 2016) and its benefits in quantity surveying firms in Nigeria has been affirmed (Awodele et al., 2015). The growing role of knowledge has made organisations move from other management practices to KM (Okunoye, 2003; Cho \& Korte, 2014). This has lead Durst and Edvardsson (2012) to recommend that small organisations such as quantity surveying firms have to include $\mathrm{KM}$ to their daily activities so that they can stay stronger and perform better.

Studies have established that KM has been embraced in the Nigerian construction industry (Oke, Ogunsemi \& Adeeko, 2013, Zuofa, et al., 2015; Idris \& Kolawole, 2016; Idris, Bhadmus \& Kadri, 2017) as well as in quantity surveying firms (Adegbembo, et al., 2015; Awodele, Adegbembo \& Ajayi, 2015). Previous research on KM within Nigeria mainly addressed KM awareness, perception of benefits, challenges (Oke et al., 2013; Adegbembo et al., 2015; Awodele et al., 2015; Zuofa et al., 2015; Idris et al., 2017). Idris and Kolawole (2016), on the other hand, assessed the influence of $\mathrm{KM}$ success factors on organisational performance of construction firms with the focus on project managers in the construction industry. However, $\mathrm{KM}$ is still a new and evolving practice for the construction industries in developing countries like Nigeria (Idris, Ali \& Aliagha, 2015).

While a considerable number of studies have identified success factors critical to the success of KM implementation, no known study has been conducted among quantity surveyors in the southwestern region of Nigeria using the principal component method. Due to the nature and scope of quantity surveying firms and using Principal Component Analysis (PCA), this study seeks to reveal the key success factors of KM with the focus on quantity surveying firms in Nigeria.

\section{CRITICAL SUCCESS FACTORS OF KOWNLEDG MANAGEMENT}

According to Idris and Kolawole (2016), Critical Success Factors (CSF) are the processes, activities and techniques that need to be considered for the successful implementation of KM in an organisation. These processes and techniques need to be developed in an organisation for $\mathrm{KM}$ to work successfully. Implementing $\mathrm{KM}$ is crucial so organisations need to be aware of the factors which will influence the success of KM initiative. The ignorance or oversight of these factors may hinder an organisation's effort in achieving the full benefit of KM (Wong, 2005). KM success factors can be seen as facilitating factors for a KM initiative and measurement of $\mathrm{KM}$ can be used as one of the means of providing an understanding of how it should be developed and implemented (Jennex \& Olfman, 2004).

A series of researches on the CSF's inherent in KM has been carried out (Skyrme \& Amidon, 1997; Egbu et al., 2010; Abdelrahman \& Papmichail, 2016). Anantatmula and Kanungo (2007), established fourteen factors important in determining the success of a KM project. These factors are leadership, top management support, culture, strategic focus, budgetary support, communication, formalisation, collaboration, content quality, KM processes, top management involvement, technology infrastructure and measurement of results. Dalotă and Grigore (2010), on the other hand, had a deep look at the critical factors that play major roles in implementing a KM system in a small to medium-sized enterprise. These factors include leadership and support, processes and activities, motivational aids, resources, culture, information technology, strategy and purpose, measurement, organisational infrastructure, training and education, and human resource management. The 
top three factors from the findings of the research are senior management support and leadership, a knowledge friendly culture, and a clear strategy for managing knowledge while developing technological infrastructure, giving incentives to encourage KM practices and measuring the effectiveness of KM was the least.

Concurrently, Yu, Kim and Kim (2004), identified three main factor dimensions and nine factors. These are Organisational characteristics which consist of learning orientation, communication, knowledge sharing, flexibility; IT comprising of KM system quality, KM system functionality and thirdly managerial support consisting of top management support, KM reward and KM team activity. Wong (2005) outlined eleven critical factors that affect KM initiatives, which are top management support, organisational culture, information technology, organisational strategy in relation to resource and capabilities utilisation, organisational infrastructure, KM processes and activities, financial support, employee training and education, employee motivation, practices of human resource management. It was further stated that these practices would either need to be nurtured if they already existed or be developed if they were not yet in place. Akhavan, Hosnavi and Sanjaghi (2009), identified five critical factors of $\mathrm{KM}$, which are $\mathrm{KM}$ architecture and readiness, human resource management, benchmarking, and chief knowledge officer. Heisig (2009), examined 119 studies on CSF and harmonised the different CSF identified from these studies. The identified CSFs were classified into four main factors which are Human factor which is composed of culture, people and leadership; Organisation which is mainly structures and processes; Information technology and management processes which comprise of strategy and control.

Sedighi and Zand (2012), however in their research described KM critical components in a broader context. They identified these critical components from two categories. These are; the external factors which are also known as environmental factors which play an important role in implementing $\mathrm{KM}$ while and internal factors, also called organisational factors, were identified as crucial in developing KM systems. They developed a conceptual classification model of KM CSF. Yong and Mustaffa (2013) similarly noted that CSFs of KM should include both factors organisations have control over and those factors beyond the control of organisations. In more recent studies on construction infrastructure, Wang et al. (2014) described 11 factors important to the success of KM as culture, leadership and support, human resource management, training and education, organisational infrastructure, KM processes, motivational aids, resources, strategy, information technology and measurement. Similarly, in the Nigerian construction industry, Idris and Kolawole (2016) identified leadership, strategy, organisational infrastructure, culture, information technology, processes and activities, education and training and $\mathrm{KM}$ resources.

According to Heisig (2009), for successful and sustainable KM, the influence of the following key areas is important; organisation and roles, culture, Strategy and leadership, controlling and measuring, skill and motivation and information technology. Table 1 below shows a summary of CSF's identified by various authors. 
Table 1: Summary of Success Factors of KM

\begin{tabular}{|c|c|c|c|c|c|c|c|c|c|c|c|c|c|c|c|c|c|c|c|c|c|c|c|c|c|c|c|}
\hline $\mathrm{S} / \mathrm{N}$ & Success Factors & 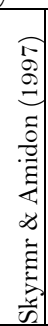 & 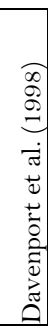 & 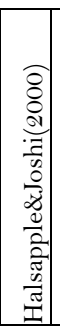 & 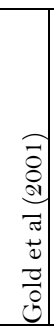 & 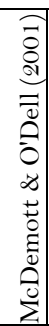 & 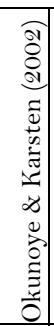 & 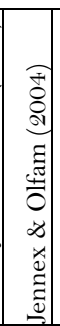 & $\begin{array}{c}0 \\
0 \\
0 \\
a \\
-0 \\
0 \\
0 \\
0 \\
0 \\
0 \\
0 \\
0 \\
0\end{array}$ & $\begin{array}{l}1 \\
0 \\
0 \\
0 \\
0 \\
0 \\
0 \\
3\end{array}$ & $\begin{array}{l}0 \\
0 \\
0 \\
0 \\
7 \\
7 \\
3 \\
3 \\
0 \\
0 \\
0 \\
0 \\
0 \\
0 \\
0 \\
3\end{array}$ & 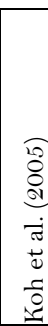 & 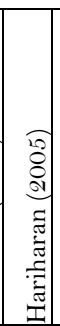 & 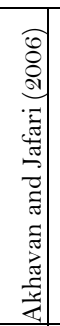 & 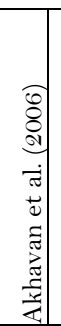 & $\begin{array}{l} \\
0 \\
8 \\
0 \\
0 \\
0 \\
0 \\
0 \\
0\end{array}$ & 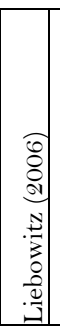 & 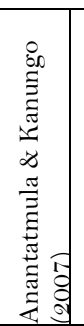 & 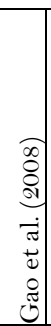 & 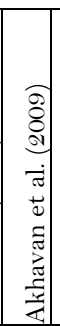 & 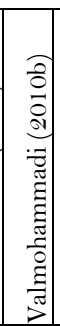 & 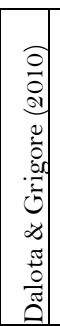 & $\begin{array}{l}\text { a } \\
0 \\
a \\
0 \\
0 \\
0 \\
0 \\
0\end{array}$ & 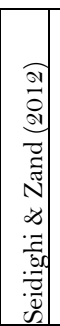 & 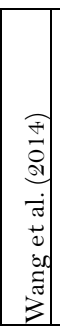 & \begin{tabular}{c|}
0 \\
0 \\
0 \\
$a$ \\
0 \\
0 \\
0 \\
0 \\
0 \\
0 \\
0 \\
0 \\
0 \\
0 \\
0 \\
0 \\
0
\end{tabular} & 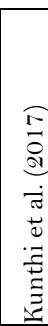 \\
\hline 1 & Organisational Strategy & $\sqrt{ }$ & $\sqrt{1}$ & - & - & - & - & - & - & $\sqrt{ }$ & $\sqrt{1}$ & - & -1 & - & - & - & $\sqrt{7}$ & - & $\sqrt{ }$ & - & $\sqrt{1}$ & $\sqrt{1}$ & $\sqrt{ }$ & $\sqrt{1}$ & $\sqrt{1}$ & $\sqrt{1}$ & - \\
\hline 2 & Leadership & $\sqrt{ }$ & - & $\sqrt{ }$ & - & - & $\sqrt{ }$ & $\sqrt{ }$ & - & - & $\sqrt{ }$ & $\sqrt{ }$ & - & - & - & - & - & $\sqrt{ }$ & - & - & $\sqrt{ }$ & $\sqrt{ }$ & - & $\sqrt{ }$ & $\sqrt{ }$ & $\sqrt{ }$ & - \\
\hline 3 & Top management support & $\sqrt{ }$ & $\sqrt{ }$ & - & - & - & - & - & - & $\sqrt{ }$ & $\sqrt{ }$ & $\sqrt{ }$ & $\sqrt{ }$ & - & $\sqrt{ }$ & - & $\sqrt{ }$ & $\sqrt{ }$ & - & - & $\sqrt{ }$ & $\sqrt{ }$ & - & - & - & - & $\sqrt{ }$ \\
\hline 4 & Organisational Culture & & $\sqrt{ }$ & - & $\sqrt{ }$ & $\sqrt{ }$ & $\sqrt{ }$ & - & - & $\sqrt{ }$ & $\sqrt{ }$ & - & $\sqrt{ }$ & - & $\sqrt{ }$ & - & $\sqrt{ }$ & $\sqrt{ }$ & - & - & $\sqrt{ }$ & $\sqrt{ }$ & - & $\sqrt{ }$ & $\sqrt{ }$ & - & $\sqrt{ }$ \\
\hline 5 & Budgetary support & - & - & - & - & - & - & - & - & - & - & $\sqrt{ }$ & - & - & - & - & - & $\sqrt{ }$ & - & - & - & - & - & - & - & - & - \\
\hline 6 & Communication & - & - & - & - & - & - & - & - & - & - & $\begin{array}{lll}- & & \\
\end{array}$ & - & - & - & - & - & $\sqrt{ }$ & - & - & - & - & - & - & - & - & \begin{tabular}{|l}
- \\
\end{tabular} \\
\hline 7 & Formalization & - & - & - & - & - & - & - & $\begin{array}{cc}- \\
\end{array}$ & - & - & 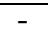 & - & - & - & - & - & $\sqrt{ }$ & - & - & - & - & - & - & - & - & - \\
\hline 8 & Collaboration & - & - & - & - & - & - & - & - & - & - & - & - & - & - & - & - & $\sqrt{ }$ & - & - & - & - & - & - & - & - & - \\
\hline 9 & KM processes/Activities & $\sqrt{ }$ & $\sqrt{ }$ & $\sqrt{ }$ & - & - & - & - & - & $\sqrt{ }$ & $\sqrt{ }$ & - & $\sqrt{ }$ & - & $\sqrt{ }$ & - & - & $\sqrt{ }$ & - & - & $\sqrt{ }$ & $\sqrt{ }$ & - & $\sqrt{ }$ & $\sqrt{ }$ & $\sqrt{ }$ & - \\
\hline 10 & $\begin{array}{l}\text { Technology infrastructure/ } \\
\text { Ontology }\end{array}$ & - & $\sqrt{ }$ & - & $\sqrt{ }$ & $\sqrt{ }$ & $\sqrt{ }$ & $\sqrt{ }$ & - & $\sqrt{ }$ & $\sqrt{ }$ & $\sqrt{ }$ & $\sqrt{ }$ & - & - & - & $\sqrt{ }$ & $\sqrt{ }$ & - & - & $\sqrt{ }$ & - & - & $\sqrt{ }$ & - & - & - \\
\hline 11 & Measurement of Result & $\sqrt{ }$ & - & $\sqrt{ }$ & - & - & $\sqrt{ }$ & - & 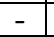 & $\sqrt{ }$ & $\sqrt{ }$ & $\sqrt{ }$ & $\sqrt{ }$ & - & - & - & - & $\sqrt{ }$ & - & - & $\sqrt{ }$ & $\sqrt{ }$ & - & - & $\sqrt{ }$ & $\sqrt{ }$ & 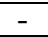 \\
\hline 12 & Motivational aid & - & - & - & - & - & - & - & - & $\sqrt{ }$ & - & 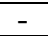 & - & - & - & - & - & - & - & - & - & $\sqrt{ }$ & - & - & $\sqrt{ }$ & - & - \\
\hline 13 & Resources & - & - & $\sqrt{ }$ & - & - & - & - & - & - & $\sqrt{ }$ & $\begin{array}{llll}- & & & \\
\end{array}$ & - & - & - & - & - & - & - & - & $\sqrt{1}$ & $\sqrt{ }$ & - & - & $\sqrt{ }$ & - & \begin{tabular}{|l}
- \\
-
\end{tabular} \\
\hline 14 & Training \& Education & - & - & - & - & - & - & - & - & $\sqrt{ }$ & $\sqrt{ }$ & - & - & - & $\sqrt{ }$ & - & - & - & - & - & $\sqrt{ }$ & $\sqrt{ }$ & - & - & $\sqrt{ }$ & $\sqrt{ }$ & - \\
\hline 15 & $\begin{array}{l}\text { Organisational } \\
\text { Infrastructure }\end{array}$ & - & $\sqrt{ }$ & - & $\sqrt{ }$ & $\sqrt{ }$ & - & - & - & $\sqrt{ }$ & - & - & - & - & - & - & $\sqrt{ }$ & - & - & - & $\sqrt{ }$ & $\sqrt{ }$ & - & - & $\sqrt{ }$ & $\sqrt{ }$ & $\begin{array}{l}- \\
-\end{array}$ \\
\hline 16 & Human Resource & - & - & - & - & - & - & - & - & $\sqrt{ }$ & $\sqrt{ }$ & \begin{tabular}{|l|}
- \\
\end{tabular} & - & - & - & - & - & - & - & $\sqrt{ }$ & $\sqrt{ }$ & $\sqrt{ }$ & - & $\sqrt{ }$ & $\sqrt{ }$ & $\sqrt{ }$ & $\sqrt{ }$ \\
\hline 17 & knowledge officers & - & - & - & - & - & - & - & - & - & - & 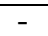 & - & - & - & - & V & - & - & $\sqrt{ }$ & - & - & - & - & - & - & - \\
\hline 18 & Information Technology & $\sqrt{ }$ & - & - & - & - & - & - & - & $\sqrt{ }$ & $\sqrt{ }$ & - & - & - & - & - & - & - & - & $\sqrt{ }$ & - & - & - & - & $\sqrt{ }$ & $\sqrt{ }$ & $\sqrt{ }$ \\
\hline 19 & Reward/Incentive & - & $\sqrt{ }$ & - & - & - & - & - & - & $\sqrt{ }$ & $\sqrt{ }$ & $-{ }_{-1}$ & - & - & - & - & $\sqrt{ }$ & - & - & - & - & - & - & - & - & - & - \\
\hline 20 & Organisational Structure & - & - & - & $\sqrt{ }$ & $\sqrt{ }$ & - & - & - & - & - & $\begin{array}{lll}- & & \\
\end{array}$ & - & - & $\sqrt{ }$ & - & - & - & - & - & - & - & - & $\sqrt{ }$ & - & - & $\sqrt{ }$ \\
\hline 21 & Transparency & - & - & - & - & - & - & - & - & - & - & - & - & - & $\sqrt{ }$ & - & - & - & - & - & - & - & - & - & - & - & - \\
\hline 22 & Trust & - & - & - & - & - & - & - & - & - & - & $\begin{array}{ll} \\
\end{array}$ & - & - & $\sqrt{ }$ & - & - & - & - & - & - & - & - & - & - & - & \begin{tabular}{|l|}
- \\
\end{tabular} \\
\hline 23 & Pilot & - & - & - & - & - & - & - & - & - & - & $\begin{array}{ll}- \\
\end{array}$ & - & - & $\sqrt{ }$ & - & - & - & - & - & - & - & - & - & - & - & - \\
\hline 24 & Bench & - & - & - & - & - & - & - & - & - & - & - & - & - & - & - & - & - & - & $\sqrt{ }$ & $\sqrt{ }$ & - & - & \begin{tabular}{|l}
- \\
\end{tabular} & - & - & - \\
\hline 25 & $\begin{array}{l}\text { KM architecture \& } \\
\text { readiness }\end{array}$ & - & - & - & - & - & - & - & - & - & - & - & - & - & $\sqrt{ }$ & - & - & - & - & $\sqrt{ }$ & - & - & - & - & - & - & - \\
\hline 26 & $\begin{array}{l}\text { Financial } \\
\text { Resources/support }\end{array}$ & - & - & - & - & - & - & - & - & - & $\sqrt{ }$ & - & - & - & - & - & - & - & - & - & - & - & - & $\sqrt{ }$ & - & - & - \\
\hline 27 & KM Strategic focus & - & - & - & - & - & $\sqrt{ }$ & - & - & - & - & $\sqrt{ }$ & $\sqrt{ }$ & - & - & - & - & $\sqrt{ }$ & - & - & - & - & - & - & - & - & - \\
\hline 28 & Content quality & - & - & - & $\begin{array}{lll}- \\
\end{array}$ & $\begin{array}{lll}- \\
\end{array}$ & - & - & 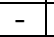 & - & - & - & $\sqrt{ }$ & - & - & - & - & $\sqrt{ }$ & - & - & - & - & - & - & - & - & - \\
\hline 29 & $\begin{array}{l}\text { Top management } \\
\text { involvement }\end{array}$ & - & - & - & - & - & - & - & - & - & - & $\sqrt{ }$ & $\sqrt{ }$ & - & - & $\sqrt{ }$ & - & $\sqrt{ }$ & - & - & - & - & - & - & - & - & - \\
\hline 30 & Employee involvement & - & - & - & - & - & - & - & $\sqrt{ }$ & - & - & - & - & - & - & $\sqrt{ }$ & - & - & - & - & - & - & - & - & - & - & - \\
\hline 31 & Teamwork & - & - & - & - & - & - & - & $\sqrt{ }$ & - & - & 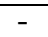 & - & - & - & $\sqrt{ }$ & - & - & 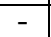 & - & - & - & - & - & - & - & $\begin{array}{ll}- \\
\end{array}$ \\
\hline 32 & werment & - & - & - & - & - & - & - & $\sqrt{1}$ & - & - & - & - & - & - & $\sqrt{ }$ & - & - & - & - & - & - & - & - & - & - & - \\
\hline 33 & $\begin{array}{l}\text { Information System } \\
\text { Infrastructure }\end{array}$ & - & - & - & - & - & - & - & $\sqrt{ }$ & - & - & - & - & - & - & $\sqrt{ }$ & - & - & - & - & - & - & - & - & - & - & - \\
\hline 34 & Knowledge Structure & - & - & - & - & - & - & - & $\sqrt{ }$ & - & - & \begin{tabular}{|l|}
- \\
\end{tabular} & - & - & - & $\sqrt{ }$ & - & - & - & - & - & - & - & - & - & - & \begin{tabular}{|l}
- \\
\end{tabular} \\
\hline
\end{tabular}




\section{METHODOLOGY}

The study is limited to quantity surveying firms in the southwestern geopolitical zone of Nigeria which comprises of six states in the country. The choice of this region is due to the high number of QS firms in the region as the region accounts for one-third of the total number of quantity surveying firms in Nigeria. One hundred and thirty-four QS firms were identified in the six states, the source of which is from the various state chapters of the Nigerian Institute of Quantity Surveying. Questionnaires were distributed to quantity surveyors both electronically via google form and personally. The questionnaire was designed having two sections. The first section was to obtain background information of both the firm and respondent, while the second section was to assess the identified CSF. Respondents were asked to rate the level of significance of the identified success factors on a 5- Likert scale where 5 represents Very High, 4 High, 3 Average, 2 Low and 1 represents Very low.

The Cronbach's Alpha test was conducted to measure the internal consistency and reliability of the measuring instrument, and a value of 0.945 was obtained. This result is greater than the 0.70 thresholds for adequacy as asserted by (Field, 2009), so, therefore, the data gathered, and result achieved should be reliable and of good quality. The data collected were analysed using the mean item score and the PCA using the International Business Machines Statistical Package for Social Sciences (IBM SPSS) version 23 to identify the inherent success factors. PCA was used in data reduction and summarisation to identify a smaller number of the CSF that explains most of the variance that is observed. It attempts to identify variables (factors) that explain the pattern of correlations within a set of observed variables. The strength of the intercorrelations was first checked among the items. Tabachnick and Fidell (2007) recommended that the correlation matrix should have coefficients greater than 0.3. the result showed a lot of items had above 0.3 coefficient. If a few correlations above this level are found, factor analysis may not be appropriate. The adequacy of the survey data was then examined by conducting the Kaiser-Meyer-Olkin (KMO) and Bartlett's test of specificity (Aghimien et al., 2018; Zhang, 2005). This represents the ratio of the squared correlation between variables to the squared partial correlation between variables. A KMO value close to 1 indicates that the patterns of correlations are relatively compact, and so factor analysis should yield a distinct and reliable result. A recommended satisfactory value for KMO, which makes factor analysis suitable is a value greater than 0.50, while Bartlett's test indicates the significance and is suitable when value is less than 0.05 (Field, 2005). The principal component method was employed to extract the factors, and varimax rotation was used to rotate the factor loading so that the factors are close to one to facilitate interpretation. The PCA clustered related CSFs of KM into groups.

\subsection{RESULT}

\subsection{Firm and Respondents Profile}

A total of $64 \%$ response rate was achieved from the 134 questionnaire distributed. From the background information, $45 \%$ of the firms surveyed had over 11 years of experience, with $39 \%$ of the firms being partnership while about $58 \%$ have more than one branches. For the profile of respondents, on the other hand, $90.7 \%$ of the respondents had a minimum of Bachelor's degree while $67.44 \%$ had practised for over five years with $62.79 \%$ being corporate members of the NIQS. This implied that most respondents had a good level of knowledge and experience which must have guided their responses.

\subsection{Assessing the Critical Success Factors of Knowledge Management}

Using the mean item score to rank the factors, the result is presented in Table 2. From table 2 , communication, top management support and top management involvement were ranked highest as success factors to the implementation of KM while the availability of knowledge 
officer, benchmarking performance and pilot (testing KM) ranked least. All 29 identified success factors had a mean above the 3-point threshold as recommended by (Kothari, 2009) and so are deemed statistically significant.

Table 2: CSF's of KM

\begin{tabular}{|c|c|c|c|}
\hline Success Factors & Mean & SD & Rank \\
\hline Communication & 4.50 & 0.628 & 1 \\
\hline Top management support & 4.45 & 0.663 & 2 \\
\hline Top management involvement & 4.43 & 0.585 & 3 \\
\hline Teamwork among employee & 4.41 & 0.692 & 4 \\
\hline $\begin{array}{l}\text { Organisational Strategy focus on Knowledge } \\
\text { Management }\end{array}$ & 4.34 & 0.696 & 5 \\
\hline KM Strategic focus & 4.31 & 0.740 & 6 \\
\hline Leadership & 4.29 & 0.734 & 7 \\
\hline Knowledge Structure & 4.27 & 0.758 & 8 \\
\hline Level of Employee involvement & 4.27 & 0.773 & 8 \\
\hline Information Technology & 4.23 & 0.714 & 10 \\
\hline Organisational Structure & 4.21 & 0.856 & 11 \\
\hline Trust & 4.21 & 0.799 & 11 \\
\hline Quality of Knowledge content & 4.20 & 0.838 & 13 \\
\hline Collaboration & 4.19 & 0.759 & 14 \\
\hline Organisational Culture & 4.17 & 0.754 & 15 \\
\hline Presence of KM processes/Activities & 4.17 & 0.870 & 15 \\
\hline Information System Infrastructure & 4.17 & 0.897 & 15 \\
\hline Reward/Incentives for knowledge sharing & 4.16 & 0.866 & 18 \\
\hline Regular Training \& Education & 4.15 & 0.976 & 19 \\
\hline Formalization & 4.14 & 0.769 & 20 \\
\hline Financial resources/Budgetary support & 4.13 & 0.905 & 21 \\
\hline Level of Employee empowerment & 4.13 & 0.905 & 21 \\
\hline Transparency in sharing knowledge & 4.12 & 0.788 & 23 \\
\hline General readiness/Resources & 4.09 & 0.916 & 24 \\
\hline Availability of Technology infrastructure/ Ontology & 4.08 & 0.961 & 25 \\
\hline Effective Human Resource Management & 4.08 & 0.985 & 25 \\
\hline Availability of knowledge officers & 4.05 & 0.866 & 27 \\
\hline Benchmarking performance/measuring result & 4.00 & 1.052 & 28 \\
\hline Pilot (Test/Sample KM) & 3.93 & 0.905 & 29 \\
\hline
\end{tabular}

\subsection{Principal Component Analysis of CSF's}

Principal components analysis was carried out on the CSFs of KM and the Kaiser-MeyerOlkin (KMO) value is 0.848 , while the Bartlett's test of sphericity is significant $(\mathrm{p}=0.000)$ making the data set suitable for factor analysis. This is as shown in table 3.

Table 3: KMO and Bartlett's Test of CSF

\begin{tabular}{|l|l|r|}
\hline \multicolumn{2}{|c|}{ KMO and Bartlett's Test } \\
\hline Kaiser-Meyer-Olkin Measure of Sampling Adequacy. & 0.848 \\
\hline Bartlett's Test of Sphericity & $\begin{array}{l}\text { Approx. Chi- } \\
\text { Square }\end{array}$ & 2620.659 \\
\cline { 2 - 3 } & df & 406 \\
\cline { 2 - 3 } & Sig. & 0.000 \\
\hline
\end{tabular}

SPSS automatically carried out a component matrix for all components with eigenvalues greater than one and all factors below one were not considered. It was decided to retain all 
five components meeting the Kaiser criterion. The result of the analysis in Table 4 showed that the first five components had initial eigenvalues greater than one. The five factors explained $75.65 \%$ of the variance being $55.40,6.05,5.41,4.67$ and 4.11 , respectively. The total percentage explained is more than the cumulative proportion of variance criterion recommended by Dogbegah et al. (2011), which affirms that extracted components should be at least $50 \%$ of the variance. So, therefore, the five components can be significantly used to represent the data.

Table 4: Total variance explained

\begin{tabular}{|l|c|c|c|c|c|c|}
\hline \multirow{2}{*}{ Comp. } & \multicolumn{3}{|c|}{ Initial Eigenvalues } & \multicolumn{2}{c|}{ Rotation Sums of Squared Loadings } \\
\cline { 2 - 7 } & Total & $\begin{array}{c}\text { \% of } \\
\text { Variance }\end{array}$ & $\begin{array}{c}\text { Cumulative } \\
\text { \% }\end{array}$ & Total & $\begin{array}{c}\text { \% of } \\
\text { Variance }\end{array}$ & $\begin{array}{c}\text { Cumulative } \\
\text { \% }\end{array}$ \\
\hline 1 & 16.066 & 55.400 & 55.400 & 5.406 & 18.642 & 18.642 \\
\hline 2 & 1.754 & 6.048 & 61.448 & 4.873 & 16.805 & 35.448 \\
\hline 4 & 1.572 & 5.419 & 66.867 & 4.584 & 15.808 & 51.255 \\
\hline 5 & 1.354 & 4.669 & 71.537 & 4.325 & 14.913 & 66.168 \\
\hline
\end{tabular}

Pallant (2011) suggested that a look at the scree plot is necessary in order to determine the components to retain. Figure 1 shows the scree plot for the CSF. From the scree plot, an elbow in the shape of the plot can be seen, and only components above this point are retained. It can be seen that there is a distinct flattening out from the sixth component downwards. The scree plot in figure 1 gives further evidence that all items with an Eigenvalue less than one can be excluded.

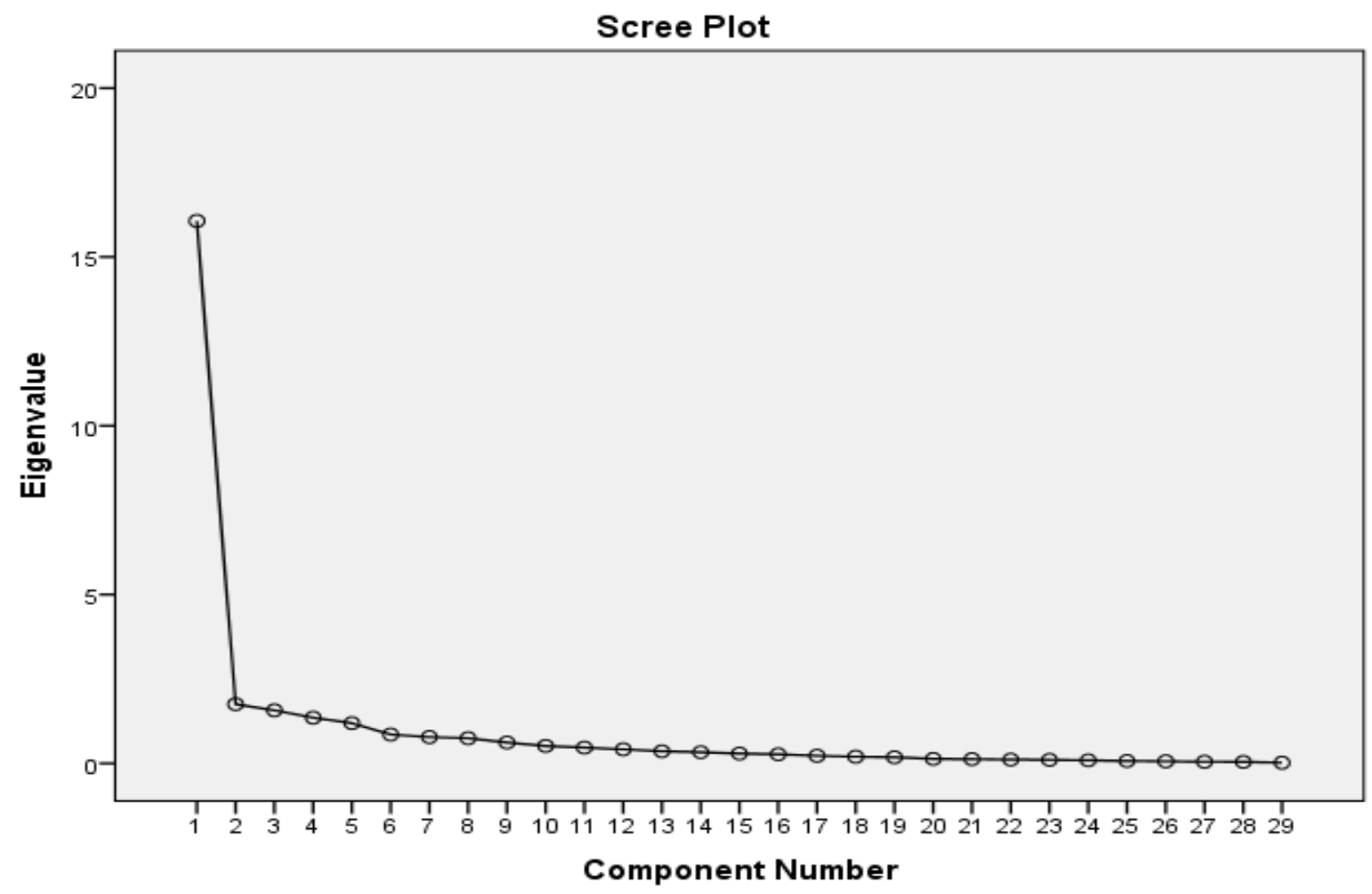

Figure 1. Scree Plot for CSF's 
Table 5: Factor Loading of the CSF's of KM

\begin{tabular}{|c|c|c|c|}
\hline & Critical Success Factors & $\begin{array}{c}\text { Factor } \\
\text { Loading }\end{array}$ & $\begin{array}{l}\text { Alpha } \\
\text { Value }\end{array}$ \\
\hline & LEADERSHIP \& STRUCTURE & & 0.870 \\
\hline $\mathrm{CSF} 28$ & Information System Infrastructure & 0.764 & \\
\hline $\mathrm{CSF} 25$ & Level of Employee involvement & 0.715 & \\
\hline CSF 15 & Availability of knowledge officers & 0.687 & \\
\hline $\mathrm{CSF} 29$ & Knowledge Structure & 0.663 & \\
\hline $\mathrm{CSF} 24$ & KM Strategic focus & 0.645 & \\
\hline CSF 19 & Trust & 0.613 & \\
\hline $\mathrm{CSF} 2$ & Leadership & 0.587 & \\
\hline $\mathrm{CSF} 26$ & Teamwork among employee & 0.573 & \\
\hline \multirow[t]{2}{*}{$\mathrm{CSF} 27$} & Level of Employee empowerment & 0.568 & \\
\hline & RESOURCES & & 0.885 \\
\hline CSF 12 & Organisational Structure & 0.765 & \\
\hline CSF 14 & Financial resources/Budgetary support & 0.694 & \\
\hline CSF3 & Top management support & 0.668 & \\
\hline CSF 13 & Effective Human Resource Management & 0.667 & \\
\hline \multirow[t]{2}{*}{$\mathrm{CSF} 1$} & Organisational Strategy focus on KM & 0.594 & \\
\hline & MANAGEMENT INVOLVEMENT & & 0.882 \\
\hline CSF6 & Formalisation & 0.776 & \\
\hline $\mathrm{CSF} 20$ & Pilot (Test/Sample KM) & 0.690 & \\
\hline $\mathrm{CSF} 22$ & Quality of Knowledge content & 0.675 & \\
\hline CSF 7 & Collaboration & 0.606 & \\
\hline CSF 18 & Transparency in sharing knowledge & 0.618 & \\
\hline $\mathrm{CSF} 23$ & Top management involvement & 0.528 & \\
\hline \multirow[t]{2}{*}{$\mathrm{CSF} 21$} & Benchmarking performance/measuring result & 0.524 & \\
\hline & INFORMATION TECHNOLOGY & & 0.903 \\
\hline $\mathrm{CSF} 8$ & Presence of KM processes/Activities & 0.756 & \\
\hline CSF 5 & Communication & 0.675 & \\
\hline CSF9 & Availability of Technology infrastructure/ Ontology & 0.615 & \\
\hline CSF 10 & General readiness/Resources & 0.611 & \\
\hline CSF 16 & Information Technology & 0.585 & \\
\hline \multirow[t]{2}{*}{ CSF 11} & Regular Training \& Education & 0.526 & \\
\hline & CULTURE & & 0.749 \\
\hline $\mathrm{CSF} 4$ & Organisational Culture & 0.746 & \\
\hline CSF 17 & Reward/Incentives for knowledge sharing & 0.528 & \\
\hline
\end{tabular}

Extraction Method: Principal Component Analysis.

Rotation Method: Varimax with Kaiser Normalisation.

a Rotation converged in 13 iterations.

The results of the factor analysis for the success factors shows that the 29 items resulted in 5 components which have been named as; Leadership \& Structure, Resources, Management involvement, Information Technology and Culture.

\section{Component 1 - Leadership and Structure}

The first component named leadership and structure is the first of the components extracted, and it explained $55.4 \%$ of the observed total variance of $75.65 \%$. This is higher than the total variance explained by all other eleven components implying that the factors loading on this component are critical. It contains nine factors that loaded as; leadership with a significance of 0.587 , availability of knowledge officers 0.687 , trust with a significance of 0.613 ; KM strategic focus 0.645 ; level of employee involvement with the sig. 0.715 ; teamwork among employee with the significance of 0.573 ; the level of employee empowerment with 
significance of 0.568; information system infrastructure 0.764 and knowledge structure with the sig. 0.663 , as shown in Table 5. All the nine items in the component had a loading above 0.5 significance value.

\section{Component 2 - Structure and Resources}

The second component is named structure and resources with $6.05 \%$ total variance explained and comprised of five variables. These items with their factor loadings are organisational strategy focus on $\mathrm{KM}(0.594)$, management support (0.668), organisational structure (0.765), effective human resource management (0.667) and financial/budgetary support (0.694). The component had a Cronbach alpha value of 0.885 .

\section{Component 3 - Management Involvement}

The third component accounted for $5.42 \%$ of the variance explained and given the name Management involvement. A total of seven variables were grouped under this component and are highly correlated as; Formalization (0.776), Collaboration (0.606), Transparency of sharing knowledge (0.618), Pilot (0.690), Benchmarking/measuring KM result (0.524), quality of knowledge content (0.675) and Top management involvement (0.528). These components had a reliability value of 0.882 .

\section{Component 4 - Information Technology}

Information technology is named as the fourth component with six variables explaining $4.66 \%$ of the variance and a corresponding reliability score of 0.903 . These variables are highly correlated, and they include communication (0.675), presence of KM processes/activities (0.756), availability of technology (0.615), general readiness (0.611), regular training and education (0.526) and information technology (0.585).

\section{Component 5 - Culture}

The last component loaded only two factors, namely organisational culture (0.746) and reward/incentive for knowledge sharing (0.528), and accounts for $4.108 \%$ of the total variance with the reliability of 0.746 . These factors were subsequently named culture.

\section{DISCUSSION}

The CSF's for the implementation of KM in quantity surveying firms was assessed, and communication, top management support and top management involvement were ranked highest as success factors to the implementation of $\mathrm{KM}$ while the availability of knowledge officer, benchmarking performance and pilot (testing $\mathrm{KM}$ ) ranked least. All identified success factors had a mean above the 3-point threshold as recommended by (Kothari, 2009) and so are all deemed statistically significant. The result of the findings is in tandem with Ekung and Okonkwo (2015), who asserted that communication and leadership are the suggested knowledge areas where the future of the quantity surveying profession can be built on. Similarly, Chhim, Somers and Chinnam (2017) concluded in their study that without toplevel leadership support, the necessary practices to develop, implement and continually support KM and especially repositories would not be well established. Drew (1997) asserted from his findings that benchmarking was one of the best tools for promoting organisational performance is in disagreement with this study as quantity surveyor rated it as the least. However, it was concluded that benchmarking may not be equally desirable or effective for all types of firms.

From the factor reduction carried out, five factors emerged and are discussed. The first component being leadership and structure had the highest variance explained by all factors, having explained $55.4 \%$ of the total variance of $75.65 \%$. This implies that all factors in the component are critical to the successful implementation of KM. Factors in this component are; Leadership, availability of knowledge officers, trust, KM strategic focus, level of employee involvement, teamwork among employee, level of employee empowerment, information system infrastructure and knowledge structure. This is in line with Pasha and Pasha (2012) assertion that leadership is critical in creating organisational mission, vision 
and objectives as well as its KM strategies. Availability of knowledge officers which has been found to be important to the success of KM in this study is in agreement with Jassen (2011), noted in its study that it is necessary to define different roles and positions in organisations to help better $\mathrm{KM}$ in organisations and this can be better done by having knowledge officers who handle all $\mathrm{KM}$ related matters within the organisation. This is also the position of Akhavan et al. (2009); however, Adegbembo et al. (2015) found that quantity surveying firms in Nigeria do not have specific unit nor specific staff responsible for KM and its needs.

The second component of the factor analysis, named Resources produced five factors grouped together. These factors are; organisational strategy focus on KM, top management support, organisational structure, effective human resource management and financial resources. Organisational strategy focus on KM as described by Jennex (2017), deals majorly with aligning KM initiative with organisations competitive strategy as well as identifying knowledge users, knowledge needed, KM metrics and incentives that are needed to ensure the use of knowledge. Aligning with Kunthi et al. (2017), Abbaszadeh (2010), top management support is one of the most influential factors in determining the success of KM. Adegbembo (2014), however, found that the support of top management is essential in overcoming the challenges of KM in QSF in Nigeria.

Management involvement factors which grouped together are formalisation, collaboration, pilot testing $\mathrm{KM}$, benchmarking performance, quality of knowledge content and top management involvement. Management can act as mentors to its employees by demonstrating and practising KM activities within the organisation (Pasha \& Pasha, 2012). Involvement implies that management practice what they preach, and since it is leadership by example, the employee tends to do as they are mentored to do and by what they see the top management does.

The six extracted factors for Information Technology component are communication, presence of KM processes, availability of technology infrastructure, general readiness, training and education and information technology. Information technology aids communication, KM activities as well as training and education within organisations. The information technology system is noted to have a positive impact on knowledge sharing, knowledge application (Choi et al., 2010) and knowledge creation (Lee et al., 2012). The use of IT, according to Khan \& Vorley (2017), has greatly changed KM practice and raised its quality.

Culture as a component comprises of organisational culture and reward/incentive for knowledge sharing. Culture according to Davenport et al. (1998); Lee and Choi (2003) is probably the most influential factor for the successful practice of KM also Egbu (2004) noted that cultural change is required to aid the total effect of $\mathrm{KM}$. These are in agreement with the study, but from Awodele et al. (2015), QSFs in Nigeria do not acknowledge that the culture of an organisation may be a challenge to successful KM practices

\section{CONCLUSION AND RECOMMENDATIONS}

Quantity surveyors have acknowledged the significance of all identified CSF's for the implementation of KM in quantity surveying firms, but communication and top management support and involvement were the most significant to quantity surveyors. A good leadership and structure, management involvement, availability of resources, information technology and culture are the most critical factors in the implementation of KM. From the findings and conclusions emanated from this study, it is recommended that quantity surveying firms should continue to recognise the importance of good leadership and structure, making resources available, the involvement of management, information technology and culture in developing successful KM practices. 


\section{REFERENCES}

Abbaszadeh, M. A. (2010). Causal model of critical success factors for knowledge management implementation, International Conference on Education and Management Technology.

Abdelrahman, M. \& Papamichail, K. (2016). The Role of Organisational Culture on Knowledge Sharing by Using Knowledge Management Systems in MNCs. In 22nd American Conferenceon Information Systems in San Diego 11-14 August

Adegbembo, T. F., Awodele, O. A. \& Ogunsemi, D. R. (2015). Assessment of knowledge management Practices in Quantity Surveying Firms in Lagos and Abuja, Nigeria. Journal of Information and Knowledge Management, 5(11), 11-19

Adegbembo, T. F. (2014). Appraising knowledge management practices in Quantity Surveying Firms in Lagos and Abuja, Nigeria. Thesis submitted to the Department of Quantity Surveying, Federal University of Technology, Akure.

Aghimien, D. O., Adegbemo, T. F., Aghimien, I. E., and Awodele, A. O., (2018). Challenges of Sustainable Construction: A Study of Educational Buildings in Nigeria. International Journal of Built Environment and Sustainability, 5(1), 33-46

Akhavan, P. \& Jafari M. (2006). Critical Success Factors of Knowledge Management Implementation at A National Level. VINE Journal of Information and Knowledge Management Systems, 36, 52-66.

Akhavan, P., Hosnavi, R. \& Sanjaghi M. (2009). Identification of Knowledge Management Critical Success Factors in Iranian Academic Research Centers. Education, Business and Society. Contemporary Middle Eastern Issues, 2(4), 276-288.

Akhavan, P., Jafari M. \& Fathian, M. (2006). Critical Success Factors of Knowledge Management Systems: A Multi-Case Analysis. European Business Review, 18(2), 97113

Anantatmula, V. S. \& Kanungo, S. (2007). Modelling Enablers for Successful Knowledge Management Implementation, Proceedings of the 40th Hawaii International Conference on System Sciences

Awodele O. A, Adegbembo T. F \& Ajayi M. O. (2015) Benefits and Challenges of Knowledge Management Practices in Quantity Surveying Firms in Nigeria: Quantity Surveyors Perspective. Lagos Journal of Environmental Science, 7(3), 53-63.

Chhim, P. P, Somers, T. M. \& Chinnam, R. (2017). Knowledge reuse through electronic knowledge repositories: a multi theoretical study, Journal of Knowledge Management, https://doi.org/10.1108/JKM-03-2016-0126

Choi, S. Y., Lee, H., \& Yoo, Y. (2010). The Impact of Information Technology and Transactive Memory Systems on Knowledge Sharing, Application, and Team Performance: A Field Study. MIS Quarterly, 34(4), 855-870.

Chong, S. C. \& Choi, Y. S. (2005). Critical factors of knowledge management implementation success, Journal of Knowledge Management Practice, available at: www.tlainc.com/articl90.htm. Retrieved $11^{\text {th }}$ August, 2017

Chong, S.C. (2006). Knowledge Management Critical Success Factors: A Comparison of Perceived Importance Versus Implementation in Malaysian ICT companies, The Learning Organisation: An International Journal, 13(3), 230-256.

Dalota, M. \& Grigore, S. (2010). Successful implementation of knowledge management in small and medium enterprises, Managerial Challenges of contemporary society, 6(1), 46-49.

Davenport, T. H., De Long, D. W. \& Beers, M. C. (1998). Successful Knowledge Management Project. Solan Management Review, 39(2), 43- 57

Dogbegah, R., Owusu-Manu, D. \& Omoteso, K. (2011) 'A principal component analysis of project management competencies for the Ghanaian construction industry', Australasian Journal of Construction Economics and Building, 11(1), 26-40. 
Egbu, C. (2004). Managing knowledge and intellectual capital for improved organisational innovations in the construction industry: An examination of critical success factors, Engineering, Construction and Architectural Management, 11, 301-315.

Egbu, J U, Wood, G. \& Egbu, C. (2010). Critical success factors associated with effective knowledge sharing in the provision of floating support services in sheltered housing for the elderly. In: Egbu, C. (Ed) Proceedings at the 26th Annual ARCOM Conference, 6-8 September 2010, Leeds, UK, Association of Researchers in Construction Management, 849-857.

Ekung, S. \& Okonkwo, E. (2015). Trend in Influences on Career Choice in Quantity Surveying and its Implications, International Journal of Education, 3(1), 1-9

Field, A. (2005) Discovering Statistics Using SPSS, 2nd ed., Sage,London.

Field, A. (2009) Discovering Statistics Using SPSS for Windows, 3rd ed., Sage Publications, London.

Gao, F, Li, M. \& Clarke, S. (2008). Knowledge, Management, and Knowledge Management in Business Operations, Journal of Knowledge Management, 12, 3-17.

Gold, A. H., Malhotra, A. \& Segars, A. H. (2001). Knowledge Management: An Organisational Capabilities Perspective. Journal of Management Information System.18(1), 185-215.

Hari, S., Egbu, C. \& Kumar, B. (2005). A knowledge capture awareness tool, Engineering, Construction and Architectural Management, 12 (6), 533 - 567

Heisig, P. (2009). Harmonisation of Knowledge Management - Comparing 160 Frameworks around the Globe. Journal of Knowledge Management, 13(4), 4-31

Holsapple, C. W. \& Joshi, K.D. (2000). An Investigation of Factors that Influence the Management of Knowledge in Organisations. Journal of Strategic Information Systems, 9, 235-261.

Hsu, I. C. (2008). Knowledge sharing practices as a facilitating factor for improving organisational performance through human capital: A preliminary test. Expert Systems with Applications. 35(3), 1316-1326

Idris, K. M. \& Kolawole, A. R. (2016). Influence of Knowledge Management Critical Success Factors on Organisational Performance in Nigerian Construction Industry, Ethiopian Journal of Environmental studies and Management, 9(3), 315-325

Idris, K., Ali, K. \& Aliagha, G. (2015). Knowledge Management Model and Instrument for Implementation and Adoption; Perspective of Developing Country. Journal of Management Research. 7(2), 548-560.

Idris, K. M, Bhadmus, R. T. \& Kabir, B. (2017). Knowledge Management Practice in Nigerian Construction Industry. Proceedings at the Nigerian Institute of Quantity Surveyors 3rd Research Conference (NIQSRecon3) 25th - 27th September

Jennex, M. E. \& Olfman, L. (2004). Assessing Knowledge Management Success/Effectiveness Models. Proceedings of the 37th Hawaii International Conference on System Sciences.HICSS37, IEEE Computer Societys

Jennex, M. E. (2017). Re-Examining the Jennex Olfman Knowledge Management Success Model, Proceedings of the 50th Hawaii International Conference on System Sciences. 4375-4384 URI: http://hdl.handle.net/10125/41691

Khan, Z. \& Vorley, T. (2017). Big data text analytics: An enabler of knowledge management, Journal of Knowledge Management, 21 (1), 18-34.

Kothari, C. R. (2009). Quantitative Techniques. (3rd ed.). New Delhi: Vikas Publishing House Pvt Limited

Kunthi, R., Sensuse, D. I. \& Tobing, R. P. (2017). Critical Success Factors of the Implementation of Knowledge Management at PT XYZ. Advances in Economics, Business and Management Research (AEBMR), 55, 29-38 
Lee, H. \& Choi, B. (2003.) Knowledge Management Enablers, Processes, and Organisational Performance: An Integrative View and Empirical Examination, Journal of Management Information Systems, 20(1),179-228

Oke A. E., Ogunsemi D. R., Adeeko O. C. (2013). Assessment of Knowledge Management Practices among Construction Professionals in Nigeria, International Journal of Construction Engineering and Management, 2(3), 85-92. doi: 10.5923/j.ijcem.20130203.06.

Okunoye, A. (2003). Context-Aware Framework of Knowledge Management: Cultural and Infrastructural Considerations. University of Turku and TUCS, Finland

Okunoye, A. \& Karsten, H. (2002). Where the global needs the local: Variation in enablers in the Knowledge management process. Journal of Global Information Technology Management, 5(3), 12-31

Oluikpe, P. (2012). Developing a corporate knowledge management strategy. Journal of Knowledge management, 16(6), 862- 878

Omotayo, F. O. (2015). Knowledge management as an important tool in organisational management: A review of literature. Library Philosophy and Practice (e-journal) 1238, $1-23$

Pallant, J. (201 1). SPSS Survival Manual: A Step by Step Guide to Data Analysis using SPSS (4th ed.). China: Everbest Printing Company

Pasha, M. A. \& Pasha, S. (2012). A Pragmatic Approach for Implementing Knowledge Management in Pakistani Organisations using Open Source Technologies. International Journal of Computer Applications, 49(7), 10-18

Sedighi, M. \& Zand, F. (2012). Knowledge Management: Review of the critical success factors and development of a conceptual classification model. Proceedings of the 10th International Conference of ICT and Knowledge Engineering, IEEE Explore pp. 1-9.

Wang, J., Li, Z. \& Tam, V. W. (2014). Critical Factors in Effective Construction Waste Minimisation at the Designs Stage: A Shenzhen Case Study, China, Resources, Conservation and Recycling, 82, 1-7

Wong, K. \& Aspinwall, E. (2006). An Empirical Study of the Important Factors for Knowledge-Management Adoption in The SME Sector. Journal of Knowledge management, 9(3), 64-82.

Wong, K. (2005). Critical Success Factors for Implementing Knowledge Management in Small and Medium Enterprises. Industrial Management \& Data Systems, 105(3), 261279.

Yong, Y. C. \& Mustaffa, N. E. (2013). Critical Success Factors for Malaysian Construction Projects: An Empirical Assessment, Construction Management and Economics, 31(9), 959-978

Yu S, Kim Y. \& Kim M. (2004). Linking Organisational Knowledge Management Drivers to Knowledge Management Performance: An Exploratory Study. HICSS37, IEEE Computer Society

Zhang, T., Wang, W. Y. C. \& Pauleen, D. J. (2017). Big data investments in knowledge and non knowledge intensive firms: What the market tells us, Journal of Knowledge Management, 21 (3), 623-639

Zuofa, T. Ochieng, E. \& Burns, A. (2015). Appraising Knowledge Management Perception among Construction Practitioners. Proceedings of the Institution of Civil Engineers Management, Procurement and Law, 168 (2), 89-98 